\title{
A informação como fenômeno interdisciplinar
}

\author{
La información como fenómeno interdisciplinario \\ Information as interdisciplinary phenomenon
}

\author{
Thais Lima Trindade \\ Universidade Federal do Amazonas. Faculdade \\ de Informação e Comunicação. Departamento de \\ Biblioteconomia, Brasil \\ thaisbibliotecaria@gmail.com \\ (iD https://orcid.org/0000-0002-0372-4245 \\ Thiago Giordano de Souza Siqueira \\ Universidade Estadual Paulista "Júlio de Mesquita Filho". \\ Faculdade de Filosofia e Ciências. Programa de Pós- \\ Graduação em Ciência da Informação, Brasil \\ thiago.giordano@unesp.br \\ (iD) https://orcid.org/0000-0001-7364-100X
}

\section{Resumo:}

O conceito de informação não é facilmente definido no âmbito da ciência da informação e mesmo para outros domínios da ciência. Vista como um conceito polissêmico com abordagens qualitativas e quantitativas ligadas à biblioteconomia, à informática, à computação, à psicologia, à comunicação, à arquivologia, à museologia, entre outras várias disciplinas, que variam. Esse trabalho convida a reflexão para gerar um debate sobre a informação como fenômeno interdisciplinar e abordado no campo da ciência da informação.

PalaVras-ChaVe: Estudos de informação, Informação, Ciência da informação, Interdisciplinaridade.

\section{Resumen:}

El concepto de información no se define fácilmente dentro del ámbito de las ciencias de la información e incluso para otros campos de la ciencia. Visto como un concepto polisémico con enfoques cualitativos y cuantitativos ligados a bibliotecología, informática, computación, psicología, comunicación, archivología, museología, entre otras materias, que varían. Este trabajo invita a la reflexión para generar un debate sobre la información como fenómeno interdisciplinario y abordado dentro del campo de las ciencias de la información.

Palabras ClaVe: Estudios de información, Información, Ciencia de la información, Interdisciplinariedad.

\section{ABSTRACT:}

The concept of information is not easily defined within the scope of information science and even for other fields of science. Seen as a polysemic concept with qualitative and quantitative approaches linked to librarianship, informatics, computing, psychology, communication, archivology, museology, among other varied disciplines. This work invites reflection to generate a debate on information as an interdisciplinary phenomenon and addressed within the field of information science.

KEYWORDS: Information studies, Information science, Information, Interdisciplinarity.

A crescente urbanização ocorrida na transição do século XVIII ao século XIX, no contexto social, assim como as práticas sociais têm experimentado transformações que permitiram no mundo pós-moderno múltiplas mudanças derivadas da globalização, consequentemente se iniciou uma tendência unificadora de 
sociedades e puderam contribuir ao desenvolvimento e intensificação dos processos de produção e o intercâmbio de informação.

É verdade que o termo informação é polissêmico e de acordo com Le Coadic (2004, p. 3) "Informação é uma medida da organização de um sistema" ou é até a organização dos códigos de uma mensagem em um caso, de acordo com uma proposta teórica divulgada por Claude Shannon e Warren Weaver no final da década de '40 em que questionavam sobre a transmissão e o processamento de informações, por meio da Teoria Matemática da Comunicação também conhecida como Teoria da Informação.

Uma concepção mais ampla em linhas gerais foi apresentada por Capurro \& Hjordland (2007, P. 187) segundo os quais:

Informação é qualquer coisa que é de importância na resposta a uma questão. Qualquer coisa pode ser informação. Na prática, contudo, informação deve ser definida em relação às necessidades dos grupos-alvo servidos pelos especialistas em informação, não no modo universal ou individualista, mas, em vez disso, de modo coletivo ou particular.

Essa definição apresenta um conceito que nos proporciona uma compreensão abrangente por se articular e incorporar a vários campos do conhecimento, uma vez que sugere o papel da informação e seu caráter informativo relacionado às práticas sociais.

As mudanças na área ao logo do tempo são indicadas como tendências contemporâneas ao que se relaciona com interdisciplinaridade, conceitos, terminologia e mesmo ao objeto informação em sua relação com dados e conhecimento. Ou seja, houve uma abertura interdisciplinar inovadora a partir do momento em que mudou a estrutura (forma de registro e organização) da informação.

Dessa forma, também contém um elemento de significado. É algo que permite atribuir um significado a uma consciência transmitida por uma mensagem inserida por um sistema de sinais (linguagem) - que combina um significante com um significado encontrado em um suporte espaço-temporal (impresso, ou um sinal elétrico etc.). Assim, se pode entender o porquê de ser um conceito polimórfico dentro de um campo interdisciplinar de estudo.

Do mesmo modo, “[...] Sabemos que, dependendo do contexto, haverá uma variação conceitual acentuada, cujos efeitos de sentido, não raro, induzem significados fracamente discriminatórios que distorcem o entendimento das principais questões em jogo” (Kobashi \& Tálamo, 2003, p. 9).

Nota-se, a importância de assegurar a compreensão das instruções ou os seres em seu significado, ou seja, o conhecimento permanece; e os meios de transmissão são o suporte da estrutura. O exemplo mais simples é a informação, a notícia publicada pelo jornal, rádio ou televisão. De fato, podemos dizer que as informações fazem parte de um sistema de representação lógica dos conteúdos registrados em um meio e que o sujeito deve fazer sentido para confirmar ou refutar seus conhecimentos prévios.

Nesse sentido, o aumento do conhecimento ocorre a partir da contextualização da informação. Diante tais aspectos, observa-se a ênfase nos fenômenos de relevância e interpretação, visão objetiva herdada da teoria matemática da informação. Em todos os casos, pode-se observar a complexidade das informações vinculadas ao contexto da Ciência da Informação e na documentação científica que, por esse motivo, se tornou objeto desse campo de estudo.

Observa-se que a informação é uma ferramenta essencial para estudantes e pesquisadores, como explicitamente flui nos processos de construção do conhecimento. No entanto, devem ser criados mecanismos que proporcionem o acesso a eles para que esses possam tomar decisóes no momento certo, responder perguntas, incentivar novas pesquisas científicas e desenvolvimento, entre outros.

Por isso, para a ciência, que de forma geral se utiliza de diversas abordagens e metodologias dos mais diversos campos de estudo, o fazer científico na contemporaneidade consiste na interação de saberes, estabelecendo relações e conexões com as mais diversas áreas do conhecimento, a chamada interdisciplinaridade. De tal maneira, o conhecimento científico, por ser de caráter temporário e mutável, está sempre aberto a novas investigações e interpretações acerca de seus fenômenos, o que emana a necessidade dessa integração de 
teorias e conhecimentos oriundo de várias áreas, evidenciando a importância da interdisciplinaridade no fazer científico.

Busca-se a interdisciplinaridade nas ações, pois a sociedade passa continuamente por divisão social e técnica do trabalho conforme as demandas emergem tornado complexas as relações, que muitas vezes não são compreensíveis de forma isolada sob perspectiva da realidade social existente.

Nessa ordem de ideias, ao reforçar o entendimento de que a Ciência da Informação estuda as propriedades como natureza, gênese e os efeitos dos processos e sistemas de construção, comunicação e utilização da informação, Le Coadic (2004, p. 20), escreve que a "[...] interdisciplinaridade traduz-se por uma colaboração entre diversas disciplinas, de modo que haja um enriquecimento mútuo".

No entanto, não existe um conceito tão firme e fácil de ser entendido por profissionais e pesquisadores para as distintas áreas, e, sobretudo, para a ciência da informação que vem a certo tempo tentando consolidar a informação como objeto de estudo. Uma das razões é por se tratar de um termo polissêmico que muda de significado em diferentes áreas em que pode ser vinculado, pois é interdisciplinar. Essa medida ocorre devido ao fato de as dimensões do conceito de informação serem múltiplas. Isso permite que a ciência da informação progrida em seu desenho teórico e, portanto, descubra e analise a informação sob diferentes ângulos como seu objeto de estudo.

Segundo Araújo (2014), as relações interdisciplinares existentes na ciência da informação remontam desde os primeiros estudos definidos sobre o tema, e desde seu início apresenta-se como uma característica "natural da área”, visto que era justificada pela contribuição de várias disciplinas provindas dos mais diversos campos do conhecimento. $\mathrm{O}$ autor ressalta ainda que o fato de a ciência da informação oferecer serviços de informação para todas as áreas do conhecimento, também compunha a justificativa do caráter interdisciplinar como sendo fator nativo da ciência da informação.

Nesse processo, a informação como matéria prima do conhecimento e produto da ação humana presente em inúmeros contextos (político, científico, cultural, religioso, tecnológico e entre outros), recebe significado e aplicação de acordo com cada campo inserido, o que torna a informação passível de estudos e análises por diversos prismas e inviabiliza uma única e legítima definição a respeito do tema.

Essa diversidade de significados e visões acerca da informação e de seus processos tem contribuído para construção da ciência da informação como disciplina, conforme aponta Borko (1968) quanto à essência da interdisciplinaridade nos estudos em informação:

É uma ciência interdisciplinar derivada de campos relacionados, tais como a Matemática, Lógica, Linguística, Psicologia, Ciência da Computação, Engenharia da Produção, Artes Gráficas, Comunicação, Biblioteconomia, Administração, e outros campos científicos semelhantes. Têm ambos os componentes, de ciência pura visto que investiga seu objeto sem considerar sua aplicação, e um componente de ciência aplicada, visto que desenvolve serviços e produtos (Borko, 1968, p. 2).

Compreender a informação e os processos relacionados ao seu tratamento, transmissão e utilização demandam a necessidade de um conjunto de conhecimentos que envolvem diversas áreas de investigação, gerando uma série de questionamentos e possibilidades nas quais a interdisciplinaridade se apresenta como uma resposta a essa complexidade. Diante a essa necessidade, a interdisciplinaridade tornou-se característica essencial para a construção e consolidação da ciência da informação. Quanto a esta assertiva, podem-se destacar as colocações de Saracevic (1996) a respeito do assunto:

A interdisciplinaridade foi introduzida na CI pela própria variedade da formação de todas as pessoas que se ocuparam com os problemas descritos. Entre os pioneiros havia engenheiros, bibliotecários, químicos, linguistas, filósofos, psicólogos, matemáticos, cientistas da computação, homens de negócios e outros vindos de diferentes profissões ou ciências. Certamente, nem todas as disciplinas presentes na formação dessas pessoas tiveram uma contribuição igualmente relevante, mas essa multiplicidade foi responsável pela introdução e permanência do objetivo interdisciplinar na CI (Saracevic, 1996, p. 8).

Dentre as relações interdisciplinares da informação com as demais áreas científicas, evidencia-se primeiramente a biblioteconomia, que inicialmente, juntamente com a documentação, subsidiaram os 
primeiros estudos relacionados à informação. Sendo sua contribuição considerada de caráter instrumental e voltada, principalmente, às questóes técnicas - a biblioteconomia compartilha com a ciência da informação o papel social da informação e as questões que envolvem a utilização e os registros da informação.

Quanto à relação com a ciência da computação, dá-se pelo uso dos computadores e das tecnologias atreladas a automatização dos processos de recuperação da informação, oportunizando, assim, diversos modelos de estudo para investigações em ciência da informação.

Em seguida, elenca-se a comunicação, que compartilha com a informação o interesse em questões similares, tais como: comportamento na busca de informação, interação do homem com tecnologias da comunicação, colégios invisíveis, sociedade da informação, entre outros (Saracevic, 1996).

Destacam-se aqui ainda as contribuições da matemática e da lógica matemática, que nortearam os estudos sobre a análise dos sistemas de informação, bem como a operação, o armazenamento e a recuperação da informação.

A teoria matemática da comunicação, que aliada à cibernética, forneceu subsídios à compreensão dos problemas existentes nos processos de interação entre as partes que compõem um sistema de informação e processamento da informação.

A linguística e a semiótica, que subsidiam os estudos das linguagens para recuperação e o armazenamento da informação nos sistemas de indexação, buscam estabelecer padrões nos registros das informações e conferir um maior índice de recuperação da informação. Ao apontar a linguística, sob a perspectiva da linguagem que, especificamente, está relacionada ao paradigma cognitivo da ciência da informação, é necessário resgatar o modelo social de nossos procedimentos que atuam de modo a entender a informação por parte das comunidades de usuários que vivem em sociedade e organizam-se com práticas individuais e coletivas, apropriação de textos pelos leitores em cada período histórico.

$\mathrm{E}$, por fim, as relações interdisciplinares com a administração que se direcionam às questões relacionadas à gestão do conhecimento e da informação, bem como à inteligência competitiva.

A organização da informação, assim como a própria ciência da informação em seu caráter interdisciplinar, naturalmente dialoga com o domínio estudado. Isso ocorre pela necessidade de entender o domínio do que se pretende organizar e comunicar e para isso busca conhecer os conceitos, a estrutura do domínio e as interrelações conceituais que são fundamentais para a elaboração de um sistema de classificação.

Ao olhar os caminhos da interdisciplinaridade da informação como um fenômeno, se pode estar de acordo com Marijuán (1994, p. 1, tradução nossa):

Mas, o que é informação? Pelo menos do ponto de vista científico, a informação aparece como um item vago e incoerente. A informação pertence àquela (não tão rara) categoria de termos científicos que, após sua cunhagem bem-sucedida, sofrem tanto abuso e superextensão que se segue um abandono factual da pesquisa, não importa o brilho aparente ou aceitação social. Melhor dizendo, em vez da discussão de um único conceito particularizado, a informação torna-se a aventura intelectual de desenvolver uma ciência "vertical" conectando as diferentes escalas de "processos informacionais" - lembrando a própria física, que a partir de um termo particularizado pré-galileu evoluiu em direção a uma ciência vertical conectando as ocorrências "celestiais", "sublunares" e "terrestres" previamente separadas. ${ }^{1}$

Dessa forma, reavaliar o próprio status da informação dentro do sistema das ciências, considerando que pode existir convergências e divergências entre as diferentes perspectivas científicas envolvidas.

Certamente, as relações citadas são as que exercem maior destaque na ciência da informação, porém, cabe salientar que existem inúmeras outras relações da informação com as mais diversas áreas, podendo ser considerada um enigma de férteis discussões em que todas as contribuições possuem seu grau de importância e não podem ser descartadas.

Conforme o exposto, a informação como objeto de estudo interdisciplinar possui inúmeros contextos e acepções, o que geram vastas e diversificadas discussões entre suas relações com as mais variadas ciências. Tal contexto permite à ciência da informação o benefício de dispor dos conhecimentos e métodos das 
demais disciplinas, se envolvendo e desenvolvendo conhecimentos nos campos científicos, tecnológicos, educacionais, sociais, culturais, entre outros.

\section{REFERÊNCIAS}

Araújo, C. A. Á. (2014). O que é ciência da informação? Informação \& informação, 19(1), 01-30. Recuperado de http ://www.uel.br/revistas/uel/index.php/informacao/article/view/15958

Borko, H. (1968). Information science: what is it? American documentation, 19(1), 3-5.

Capurro, R. \& Hjordland, B. (2007). O conceito de informação. Perspectivas em ciência da informação, 12(1), 148-207.

Kobashi, N. Y. \& Tálamo, M. F. G. (2003). Informação: fenômeno e objeto de estudo da sociedade contemporânea. Transinformação, 15(esp.), 07-21. https://doi.org/10.1590/S0103-37862003000500001

Le Coadic, Y. F. (2004). A ciência da informação. Brasília: Briquet de Lemos.

Marijuán, P. C. (1994, Julho). Presentation. In Proceeding of Foundations of Information Science. Madrid, Espanha. Recuperado de https://web.archive.org/web/20010404234504/http://fis.iguw.tuwien.ac.at/

Saracevic, T. (1996). Ciência da informação: origem, evolução e relações. Perspectivas em ciência da informação, 1(1), 41-62. Recuperado de http://portaldeperiodicos.eci.ufmg.br/index.php/pci/article/view/235

\section{Notas}

1. Original text: But, what is information? At least from the scientific point of view, information appears as a vague and incoherent item. Information belongs to that (not so rare) category of scientific terms which, after their successful coinage, suffer so much abuse and overextension that a factual abandonment of research ensues, no matter the apparent brilliancy or social acceptance. [...] So to speak, instead of the discussion of a single particularized concept, information becomes the intellectual adventure of developing a 'vertical' science connecting the different scales of 'informational processes' --reminding physics itself, which from a pre-Galilean particularized term evolved towards a vertical science connecting the previously separated "celestial", "sublunar", and "terrestrial" occurrences. 